Pacific Journal of Mathematics

A FACTORIZATION THEOREM FOR ANALYTIC FUNCTIONS 


\title{
A FACTORIZATION THEOREM FOR ANALYTIC FUNCTIONS OPERATING IN A BANACH ALGEBRA
}

\author{
Philip C. Curtis, JR. AND Henrik StetKaer
}

\begin{abstract}
Cohen's factorization-theorem asserts that if the Banach algebra $\mathfrak{A}$ has a left approximate identity, then each $y \in \mathfrak{A}$ may be written $y=x z, x, z \in \mathfrak{A}$. The vector $x$ may be chosen to be bounded by some fixed constant and $z$ may be chosen arbitrarily close to $y$. In this setting the theorem below asserts that if $F$ is a holomorphic function defined on a sufficiently large disc about $\zeta=1$, and satisfying $F(1)=1$, then each $y \in \mathfrak{A}$ may be written $y=F(x) z$, where $x, z \in \mathfrak{A}$. Again $x$ may be chosen to be bounded by some fixed constant and $z$ may be chosen close to $y$.
\end{abstract}

We state and prove our result using the terminology of [2]. The proof is an elaboration of the proof of Theorem 2.2 of [2]. In what follows $X$ is a complex Banach space, $\mathscr{E}=\left\{E_{\alpha}\right\}$ is a uniformly bounded subset of $B(X)$ which we may assume to be directed and which satisfies $\lim _{\alpha} E_{\alpha} E=E$ for each $E \in \mathscr{E}$. Convergence is in the norm topology of $B(X)$. Let

$$
Y=\left\{x \in X: \lim _{\alpha} E_{\alpha} x=x\right\},
$$

and let $\mathfrak{i}$ be the closed subalgebra of $B(X)$ generated by $\mathscr{E}$.

For further extensions of Cohen's theorem we refer the reader to Chapter 8 of [3].

THEOREM. Let $F$ be a holomorphic complex-valued function with $F(1)=1$, defined on a neighbourhood of $\{z \in C|| z-1 \mid \leqq M\}, M>1$, where $\|E-I\| \leqq M$ for all $E \in \mathscr{E}$.

Then to every $y \in Y$ and $\delta>0$ there exist $z \in Y$ and $U \in \mathfrak{V}$ such that

$$
y=F(U) z \text { and }\|y-z\|<\delta .
$$

If furthermore $F$ has no zeros in the open interval ]0, 1[, then $U$ may for some $a \in] 0,1[$ be written in the form

$$
U=\sum_{1}^{\infty} a(1-a)^{k-1} E_{k}
$$

where $E_{k} \in \mathscr{E}$ for $k=1,2, \cdots$. 
Proof. It suffices to prove the theorem in the case where $F$ has no zeros in $] 0,1[$, since we otherwise simply use the function

$$
G(z)=F\left(e^{i \theta} z\right) F\left(e^{i \theta}\right)^{-1}
$$

for $\theta$ small, instead of $F$.

Let $\left\{\lambda_{1}, \cdots, \lambda_{m}\right\}$ denote the zeros of $F$ in the disc $\{z \in C|| z-1 \mid \leqq M\}$.

Let finally $y \in Y$ and $\delta>0$ be given.

To proceed we need

Lemma 1. Let $0<a<1 ; E_{1}, \cdots, E_{n} \in \mathscr{E}$ and set

$$
U_{n}=\sum_{1}^{n} a(1-a)^{k-1} E_{k}+(1-a)^{n} I .
$$

Assume that no $\lambda_{i}$ belongs to the spectrum $\sigma\left(U_{n}\right)$ of $U_{n}$, and that

$$
R\left(\lambda_{i}, U_{n}\right) Y \leqq Y \quad \text { for } i=1, \cdots, m
$$

where

$$
R\left(\lambda_{i}, U_{n}\right)=\left(\lambda_{i} I-U_{n}\right)^{-1} .
$$

Then $F\left(U_{n}\right)$ and $W_{n} \equiv F^{-1}\left(U_{n}\right)$ belong to $B(X)$ and both map $Y$ into $Y$.

Proof. We assert first that $\sigma\left(U_{n}\right) \subseteq\{|z-1|<M\}$. Indeed,

$$
U_{n}-I=\sum_{k=1}^{n} a(1-a)^{k-1} E_{k}+(1-a)^{n} I-I=\sum_{k=1}^{n} a(1-a)^{k-1}\left(E_{k}-I\right),
$$

so that

$$
\left\|U_{n}-I\right\| \leqq M \sum_{k=1}^{n} a(1-a)^{k-1}=M\left(1-(1-a)^{n}\right)<M .
$$

Now

$$
Y=\left\{x \in X \mid \lim _{\alpha} E_{\alpha} x=x\right\},
$$

and consequently $E Y=Y$ for every $E \in \mathscr{E}$, so that $U_{n} Y \leqq Y$. For $|\zeta-1|=M$ we have

$$
\begin{aligned}
R\left(\zeta, U_{n}\right) & =(\zeta-1)^{-1}\left(I-(\zeta-1)^{-1}\left(U_{n}-I\right)\right)^{-1} \\
& =(\zeta-1)^{-1} \sum(\zeta-1)^{-k}\left(U_{n}-I\right)^{k},
\end{aligned}
$$

which converges absolutely, so that

$$
R\left(\zeta, U_{n}\right) Y \cong Y
$$

Since the integral 


$$
F\left(U_{n}\right)=\frac{1}{2 \pi i} \int_{|\zeta-1|=M} F(\zeta) R\left(\zeta, U_{n}\right) d \zeta \in B(X)
$$

is a limit of Riemann sums,

$$
F\left(U_{n}\right) Y \leqq Y .
$$

Since $F$ is holomorphic and does not vanish on $\sigma\left(U_{n}\right)$ we have

$$
W_{n} \equiv F^{-1}\left(U_{n}\right) \in B(X) \text {. }
$$

To show $W_{n} Y \subseteq Y$, write

$$
F(z)=\prod_{i=1}^{m}\left(\lambda_{i}-z\right)^{k_{i}} H(z),
$$

where $H$ does not vanish on $\{|z-1|<M$. $\}$ The above argument shows $H^{-1}\left(U_{n}\right) Y \leqq Y$. Finally,

$$
F^{-1}\left(U_{n}\right)=H^{-1}\left(U_{n}\right) \prod_{i=1}^{m} R\left(\lambda_{i}, U_{n}\right)^{k_{i}},
$$

and

$$
R\left(\lambda_{i}, U_{n}\right) Y \subseteq Y
$$

by hypothesis.

Lemma 2. If in addition $U_{n}$ may be chosen so that

$$
\left\|\left(W_{n}-W_{n-1}\right) y\right\|<\frac{\delta}{2^{n}} \quad \text { for } n=1,2, \cdots,
$$

then the theorem follows.

Proof. Set $z_{n}=W_{n} y$. Then $\left\{z_{n}\right\}$ is a Cauchy-sequence. With $z=\lim _{n} z_{n}$ we have $\|z-y\| \leqq \delta$.

Further, if

$$
U=\sum_{1}^{\infty} a(1-a)^{k-1} E_{k}
$$

then

$$
\begin{aligned}
\|F(U) z-y\| & =\left\|F(U) z-F\left(U_{n}\right) z+F\left(U_{n}\right)\left(z-z_{n}\right)+F\left(U_{n}\right) z_{n}-y\right\| \\
& \leqq\left\|F(U)-F\left(U_{n}\right)\right\|\|z\|+\left\|F\left(U_{n}\right)\right\|\left\|z-z_{n}\right\|,
\end{aligned}
$$

from which the lemma follows.

We will need the following technical lemma in the induction step below, where we use the notation

$$
\begin{gathered}
T(a)=\left\{\mu(1-a)^{-n} \mid n=0,1, \cdots \text { and } \mu \in\left\{\lambda_{1}, \cdots, \lambda_{m}\right\} \cup\{z|| z-1 \mid=M\}\right\} \\
\text { for } 0<a<1 .
\end{gathered}
$$


Lemma 3. There exists $b \in] 0,1[$ such that

$$
\left.\left.\left|a(\tau-1)^{-1}\right|<\frac{1}{2 M} \text { for all } a \in\right] 0, b\right] \text { and all } \tau \in T(\alpha) \text {. }
$$

Let $A_{\alpha}=a E_{\alpha}+(1-a) I$ for some $\left.\left.a \in\right] 0, b\right]$. Then for $\tau \in T(a)$ we have that $R\left(\tau, A_{\alpha}\right)$ exists in $B(X)$, maps $Y$ into $Y$ and has $\left\|R\left(\tau, A_{\alpha}\right)\right\| \leqq C<\infty$, where $C$ only depends on $F$ and $M$.

Furthermore, for fixed $E \in \mathscr{E}$ and $x \in Y$,

$$
\lim _{\alpha} R\left(\tau, A_{\alpha}\right) E=(\tau-1)^{-1} E
$$

and

$$
\lim _{\alpha} R\left(\tau, A_{\alpha}\right) x=(\tau-1)^{-1} x,
$$

both uniformly for $\tau \in T(a)$.

Proof. The first assertion is an easy consequence of the fact that $F$ has no zeros in $] 0,1[$, so that

$$
|\tau-1| \geqq c>0 \text { for all } \tau \in T(a) \text { and all } a \in] 0,1[\text {. }
$$

Since

$$
\tau I-A_{\alpha}=(\tau-1)\left(I-\frac{a}{\tau-1}\left(E_{\alpha}-I\right)\right),
$$

we have that

$$
R\left(\tau, A_{\alpha}\right)=(\tau-1)^{-1} \sum_{0}^{\infty}\left(\frac{a}{\tau-1}\right)^{k}\left(E_{\alpha}-I\right)^{k},
$$

converges by our choice of $a$, maps $Y$ into $Y$ and finally that

$$
\left\|R\left(\tau, A_{\alpha}\right)\right\| \leqq \max |\tau-1|^{-1} \sum_{0}^{\infty} 2^{-k}=2 \max \left\{|\tau-1|^{-1} \mid \tau \in T(\alpha)\right\} .
$$

By an easy calculation

$$
R\left(\tau, A_{\alpha}\right)-(\tau-1)^{-1} I=\frac{a}{(\tau-1)^{2}} R\left(\tau, A_{\alpha}\right)\left(E_{\alpha}-I\right),
$$

which yields the lemma.

We will also need the following trivial lemma.

Lemma 4. Let $\left\{T_{i \alpha} \mid \alpha \in A, i=1, \cdots, n\right\} \subseteq B(Y)$ satisfy

$$
\left\|T_{i \alpha}\right\| \leqq C<\infty \quad \text { for all } \alpha \in A, i=1, \cdots, n \text {. }
$$

If $T_{i \alpha} \rightarrow T_{i}$ strongly for $i=1, \cdots, n$, then 


$$
T_{1 \alpha} T_{2 \alpha} \cdots T_{n, \alpha} \rightarrow T_{1} T_{2} \cdots T_{n}
$$

strongly.

We will now by induction find a sequence $\left\{E_{k}\right\} \subseteq \mathscr{E}$ such that for any fixed $a \in] 0, b]$,

$$
R\left(\lambda_{i}, U_{n}\right) \in B(X) \text { for all } i=1, \cdots, m \text { and } n=0,1, \cdots,
$$

(*) maps $Y$ into $Y$ and such that

$$
\left\|\left(W_{n}-W_{n-1}\right) y\right\|<\frac{\delta}{2^{n}} \quad \text { for } \quad n=1,2, \cdots .
$$

The theorem then follows from Lemma 2. For $n=0$ we may take $U_{0}=I$.

Now suppose we have found $U_{0}, U_{1}, \cdots, U_{n}$ satisfying (*).

Let $A_{n+1}=a E_{n+1}+(1-a) I$, where $E_{n+1} \in \mathscr{E}$ is to be chosen. define

Since $R\left(\tau, A_{n+1}\right)$ makes sense for $\tau \in T(a)$ by Lemma 3 , we may

$$
U_{n}^{\prime}(\lambda)=-\sum_{1}^{n} a(1-a)^{k-1} R\left(\lambda(1-a)^{-n}, A_{n+1}\right) E_{k}+(1-a)^{n} I
$$

for $\lambda \in T(a)$. We note that $U_{n}^{\prime}(\lambda)$ may be chosen arbitrarily close to $\left(1-\lambda(1-a)^{-n}\right)^{-1}\left(U_{n}-\lambda I\right)$ uniformly for $\lambda \in T(a)$ if we just take $E_{n+1}$ large. Therefore, $U_{n}^{\prime}(\lambda)^{-1}$ exists in $B(X)$, maps $Y$ into $Y$ and is uniformly bounded in $T(a)$ and $\mathscr{E}$ for $E_{n+1}$ large.

By an easy calculation

$$
\lambda I-U_{n+1}=\left(\lambda(1-a)^{-n} I-A_{n+1}\right) U_{n}^{\prime}(\lambda)
$$

so

$$
R\left(\lambda, U_{n+1}\right)=U_{n}^{\prime}(\lambda)^{-1} R\left(\lambda(1-a)^{-n}, A_{n+1}\right)
$$

exists in $B(X)$, maps $Y$ into $Y$ and is uniformly bounded in $T(a)$ and $\mathscr{E}$.

Since

$$
F^{-1}\left(U_{k}\right)=H^{-1}\left(U_{k}\right) \prod_{1}^{m} R\left(\lambda_{i}, U_{k}\right)^{k_{i}}
$$

it is by an easy application of Lemma 4 left to show that for each $x \in Y$,

$$
R\left(\lambda, U_{n+1}\right) x \rightarrow R\left(\lambda, U_{n}\right) x
$$

uniformly for $\lambda \in T(a)$ as $E_{n+1}$ increases in $\mathscr{E}$.

Now 


$$
\begin{aligned}
R\left(\lambda, U_{n+1}\right) x & -R\left(\lambda, U_{n}\right) x \\
= & U_{n}^{\prime}(\lambda)^{-1} R\left(\lambda(1-a)^{-n}, A_{n+1}\right) x-R\left(\lambda, U_{n}\right) x \\
= & U_{n}^{\prime}(\lambda)^{-1}\left[R\left(\lambda(1-a)^{-n}, A_{n+1}\right) x-\left(\lambda(1-a)^{-n}-1\right)^{-1} x\right] \\
& +\left[\left(\lambda(1-a)^{-n}-1\right)^{-1} U_{n}^{\prime}(\lambda)^{-1}-R\left(\lambda, U_{n}\right)\right] x .
\end{aligned}
$$

The first term can be made arbitrarily small by Lemma 3 . The second term can be made arbitrarily small too, for we have already observed that

$$
U_{n}^{\prime}(\lambda) \rightarrow\left(1-\lambda(1-a)^{-n}\right)^{-1}\left(U_{n}-\lambda I\right) \quad \text { unif. in } T(\alpha)
$$

so

$$
U_{n}^{\prime}(\lambda)^{-1} \rightarrow\left(\lambda(1-\alpha)^{-n}-1\right) R\left(\lambda, U_{n}\right) \text { unif. in } T(\alpha) .
$$

That finishes the proof.

REMARK. If $K$ is a compact subset of $Y$ then we can use the same $U$ for all $y \in K$. That is proved as in [5].

Similarly, if $y_{i} \rightarrow 0$, then there exist $U$ and $x_{i}, x_{i} \rightarrow 0$ such that $y_{i} \in F(U) x_{i}$.

Corollary. Let $A$ be a commutative self-adjoint semi-simple Banach algebra with a bounded approximate identity $\left\{e_{\alpha}\right\}$. Let $\mathscr{M}_{A}$ be the maximal ideal space for $A$. If $f \in C_{0}\left(\mathscr{M}_{A}\right)$, the continuous complex functions on $\mathscr{M}_{A}$ vanishing at $\infty$, and $f \geqq 0$, then there exists a $g \in C_{0}\left(\mathscr{C}_{A}\right), g \geqq 0$ such that $\sqrt{f / g} \in A$. If $f \in A$, then $g$ may be chosen to be in $A$.

Proof. $f \rightarrow \bar{f}$ is continuous since $A$ is commutative and semisimple. $\left\{f_{\alpha}\right\}=\left\{e_{\alpha} \bar{e}_{\alpha}\right\}$ is an approximate identity consisting of nonnegative functions. Let $F(z)=z^{2}$ and write $f \in C_{0}\left(\mathscr{C}_{A}\right), f \geqq 0$ as $f=h^{2} g$, where $h=\sum a(1-a)^{n-1} f_{n}$ with $\left\{f_{n}\right\} \subseteq\left\{f_{\alpha}\right\}$ is in $A$. Then $h=\sqrt{f / g}$, and we are done.

This Corollary may be contrasted with a theorem of Katznelson [4] which asserts that if $\sqrt{f} \in A$ for each nonnegative $f$ in $A$ then $A=C\left(\mathscr{M}_{A}\right)$.

\section{REFERENCES}

1. Paul Cohen, Factorization in group-algebras, Duke Math. J., 26 (1959), 199-206.

2. P. C. Curtis, Jr. and Figa-Talamanca, Factorization theorems for Banach algebras in "Function algebras" edited by F. T. Birtel, Scott Foresman and Co., Chicago Ill. 1966, 169-185.

3. E. Hewitt and K. Ross, Abstract harmonic analysis, II, Springer-Verlag 1970. 
4. Y. Katznelson, Sur les algèbres dont les éléments non-negatifs admettent des racines carrés, Ann. École Norm. Sup, $3^{e}$ serie, 77 (1960), 167-174.

5. D. C. Taylor, A characterization of Banach algebras with approximate unit, Bull. Amer. Math. Soc., 74(1968), 761-766.

Received October 10, 1970

University of California, Los ANGeles

AND

AARHUS UnIVERSITY 



\section{PACIFIC JOURNAL OF MATHEMATICS}

\section{EDITORS}

\author{
H. SAMElson \\ Stanford University \\ Stanford, California 94305 \\ C. R. HOBBY \\ University of Washington \\ Seattle, Washington 98105
}

J. DugundjI

Department of Mathematics University of Southern California Los Angeles, California 90007

RICHARD ARENS

University of California

Los Angeles, California 90024

\section{ASSOCIATE EDITORS}
E. F. BECKENBACH
B. H. NeUmanN
F. WOLE
K. YOSHIDA

\section{SUPPORTING INSTITUTIONS}

\author{
UNIVERSITY OF BRITISH COLUMBIA \\ CALIFORNIA INSTITUTE OF TECHNOLOGY \\ UNIVERSITY OF CALIFORNIA \\ MONTANA STATE UNIVERSITY \\ UNIVERSITY OF NEVADA \\ NEW MEXICO STATE UNIVERSITY \\ OREGON STATE UNIVERSITY \\ UNIVERSITY OF OREGON \\ OSAKA UNIVERSITY \\ UNIVERSITY OF SOUTHERN CALIFORNIA
}

\author{
STANFORD UNIVERSITY \\ UNIVERSITY OF TOKYO \\ UNIVERSITY OF UTAH \\ WASHINGTON STATE UNIVERSITY \\ UNIVERSITY OF WASHINGTON \\ * * * \\ AMERICAN MATHEMATICAL SOCIETY \\ CHEVRON RESEARCH CORPORATION \\ NAVAL WEAPONS CENTER
}

The Supporting Institutions listed above contribute to the cost of publication of this Journal, but they are not owners or publishers and have no responsibility for its content or policies.

Mathematical papers intended for publication in the Pacific Journal of Mathematics should be in typed form or offset-reproduced, (not dittoed), double spaced with large margins. Underline Greek letters in red, German in green, and script in blue. The first paragraph or two must be capable of being used separately as a synopsis of the entire paper. The editorial "we" must not be used in the synopsis, and items of the bibliography should not be cited there unless absolutely necessary, in which case they must be identified by author and Journal, rather than by item number. Manuscripts, in duplicate if possible, may be sent to any one of the four editors. Please classify according to the scheme of Math. Rev. Index to Vol. 39. All other communications to the editors should be addressed to the managing editor, Richard Arens, University of California, Los Angeles, California, 90024.

50 reprints are provided free for each article; additional copies may be obtained at cost in multiples of 50 .

The Pacific Journal of Mathematics is published monthly. Effective with Volume 16 the price per volume (3 numbers) is $\$ 8.00$; single issues, $\$ 3.00$. Special price for current issues to individual faculty members of supporting institutions and to individual members of the American Mathematical Society: $\$ 4.00$ per volume; single issues $\$ 1.50$. Back numbers are available.

Subscriptions, orders for back numbers, and changes of address should be sent to Pacific Journal of Mathematics, 103 Highland Boulevard, Berkeley, California, 94708.

PUBLISHED BY PACIFIC JOURNAL OF MATHEMATICS, A NON-PROFIT CORPORATION

Printed at Kokusai Bunken Insatsusha (International Academic Printing Co., Ltd.), 7-17, Fujimi 2-chome, Chiyoda-ku, Tokyo, Japan. 


\section{Pacific Journal of Mathematics}

\section{Vol. 37, No. $2 \quad$ February, 1971}

Charles Compton Alexander, Semi-developable spaces and quotient images of metric spaces .................................... 277

Ram Prakash Bambah and Alan C. Woods, On a problem of Danzer. . . . . . . . . 295

John A. Beekman and Ralph A. Kallman, Gaussian Markov expectations and related integral equations . ....................................

Frank Michael Cholewinski and Deborah Tepper Haimo, Inversion of the Hankel

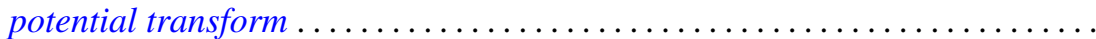

John H. E. Cohn, The diophantine equation

$$
Y(Y+1)(Y+2)(Y+3)=2 X(X+1)(X+2)(X+3) \ldots \ldots \ldots \ldots \ldots
$$

Philip C. Curtis, Jr. and Henrik Stetkaer, A factorization theorem for analytic

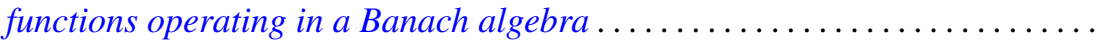

Doyle Otis Cutler and Paul F. Dubois, Generalized final rank for arbitrary limit ordinals

Keith A. Ekblaw, The functions of bounded index as a subspace of a space of entire functions

Dennis Michael Girard, The asymptotic behavior of norms of powers of

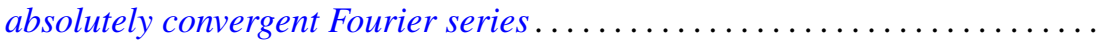

John Gregory, An approximation theory for elliptic quadratic forms on Hilbert spaces: Application to the eigenvalue problem for compact quadratic forms. 383

Paul C. Kainen, Universal coefficient theorems for generalized homology and stable cohomotopy.

Aldo Joram Lazar and James Ronald Retherford, Nuclear spaces, Schauder bases, and Choquet simplexes.

David Lowell Lovelady, Algebraic structure for a set of nonlinear integral operations

John McDonald, Compact convex sets with the equal support property . 429

Forrest Miller, Quasivector topologies

Marion Edward Moore and Arthur Steger, Some results on completability in commutative rings.

A. P. Morse, Taylor's theorem

Richard E. Phillips, Derek J. S. Robinson and James Edward Roseblade, Maximal subgroups and chief factors of certain generalized soluble groups.

Doron Ravdin, On extensions of homeomorphisms to homeomorphisms ...

John William Rosenthal, Relations not determining the structure of $\mathrm{L}$

Prem Lal Sharma, Proximity bases and subbases ........... .

Larry Smith, On ideals in $\Omega_{*}^{u}$. .

Warren R. Wogen, von Neumann algebras generated by operators similar to normal operators

R. Grant Woods, Co-absolutes of remainders of Stone-Čech 